\title{
Carreira e trabalho: quem é o assessor de imprensa em Imperatriz (MA)?
}

\author{
Thaísa Cristina Bueno \\ Doutora; Universidade Federal do Maranhão, Imperatiz (MA), Brasil \\ thaisabu@gmail.com
}

Jordana Fonseca

Mestranda; Universidade Federal do Piaui, Teresina (PI), Brasil jordana.fonseca13@gmail.com

\section{Resumo}

A proposta desta pesquisa é traçar o perfil do profissional que trabalha em assessoria de imprensa em Imperatriz, segunda maior cidade do Maranhão. 0 mapeamento levanta características relacionadas à formação, à renda, às atribuições e às condições de trabalho dos profissionais que atuaram neste cargo em 2017, nesse município. Para isso, um questionário semiestruturado online, com 23 questões, foi aplicado por meio da ferramenta Google Forms e enviado para os 37 profissionais mapeados como atuantes no mercado local. Destes, 32 responderam. Os resultados apontam que o mercado de assessoria de imprensa na cidade cresceu exponencialmente nos últimos 10 anos, o que se configura, efetivamente, em mais empregos para jornalistas, ainda que precise de melhorias nas condições de trabalho e na remuneração.

\section{Palavras-chave}

Perfil profissional. Assessoria de imprensa. Imperatriz (MA). Mapeamento. Mercado de trabalho.

\section{Introdução}

A assessoria de imprensa é, efetivamente, o setor que mais emprega jornalistas em Imperatriz, a segunda maior cidade do Maranhão, com 258.016 mil habitantes de acordo com dados da última estimativa do Instituto Brasileiro de Geografia e Estatística (IBGE, 2018a). 0 estudo de Silva (2016) sobre o perfil do egresso ${ }^{1}$ do curso de Jornalismo da

\footnotetext{
${ }^{1}$ A pesquisa realizada em 2016 e que resultou na monografia intitulada Quem somos? Perfil do formado em Comunicação Social com habilitação em Jornalismo da Universidade Federal do Maranhão (UFMA) - Campus Imperatriz buscou mapear aspectos socioeconômicos, políticos, educacionais e profissionais dos graduados na instituição nos 10 anos de curso de jornalismo, em Imperatriz.
} 
Universidade Federal do Maranhão (UFMA) de Imperatriz diagnosticou, por exemplo, que 48,8\% dos ex-alunos daquela instituição estão trabalhando em assessorias. 0 dado reflete e corrobora o cenário nacional. Levantamento de Mick e Lima (2013), numa pesquisa que envolveu parceria entre a Universidade Federal de Santa Catarina (UFSC) e a Federação Nacional dos Jornalistas (Fenaj), já apontava que 40\% dos profissionais brasileiros trabalhavam em assessoria de imprensa e/ou comunicação.

Em Imperatriz, um marco determinante no mercado da Comunicação local foi a implantação do curso de Jornalismo na cidade, em 2006. Em dez anos houve uma alteração do perfil dos profissionais, com a inserção de 176 alunos formados pela UFMA e com a criação de empresas específicas para atendimento em assessoria de imprensa, como a Palavra Comunicação (fundada em 2012), a Prensa Comunicação (fundada em 2013), a Nova Assessoria de Imprensa (fundada em 2015) e a Pimenta Assessoria de Imprensa (fundada em 2017). Para atender a demanda de especialização nessa área, o primeiro curso de pósgraduação lato sensu da UFMA de Imperatriz adotou como temática a Assessoria de Imprensa Empresarial e Institucional. Com 28 alunos, a primeira turma foi constituída de profissionais de Imperatriz, mas também dos arredores, vindos dos municípios de Açailândia, São Francisco do Brejão e de outros, com formações em Comunicação, Administração, Filosofia e Letras.

Apesar de haver estudos que buscaram lançar um olhar para o mercado local, como o de Silva (2016) e o de Morais (2010), nenhum teve a assessoria de imprensa como questão de pesquisa. Nesse sentido, a proposta aqui é conhecer qual é o perfil desse profissional que está atuando na cidade de Imperatriz e como esse profissional enxerga seu trabalho. Embora autores como Duarte (2009) e Chaparro (2009) pontuem que o desenvolvimento das primeiras atividades de assessoria de imprensa remonte ao início do século passado e embora, de lá para cá, tenha havido muitas mudanças na forma de se atuar no Jornalismo, a centralidade de algumas atribuições parece ser consenso entre esses autores e entre outros, como Kopplin e Ferrareto (2009), Chinem (2003), Mafei (2008) etc., como constitutivas das funções de um assessor de imprensa. Entre essas funções, destaca-se o oferecimento de informações jornalísticas dos assessorados para veículos de comunicação, com o intuito de dar-lhe visibilidade, bem como a construção de uma imagem pública positiva desse cliente.

Sobre esse assunto, a posição de Kopplin e Ferrareto (2009) de que a atividade primeira das assessorias de imprensa é intermediar a relação entre o assessorado e a imprensa, por meio de divulgação de informações, boa parte dessas no formato de notícias, parece resumir o entendimento mais amplo do que essa função contempla. 0 próprio manual da Fenaj (2007) ratifica esse entendimento ao ponderar que o serviço da assessoria 
de imprensa consiste em oferecer atividades de envio de informações jornalísticas de instituições públicas e privadas para veículos de comunicação de diferentes suportes.

De maneira sistematizada, Chinem (2003), Mafei (2008), Martinuzzo (2013), entre outros, apresentam inventários de funções mais corriqueiras que fazem parte das atividades de um assessor de imprensa ou que se espera que ele execute. Recorrentes nas listagens desses autores estão o envio de textos à imprensa (releases, press kit, sugestões de pauta, entre outros), a atualização das listas de mídia interessantes para receber informações do assessorado (mailing atualizado), o acompanhamento das publicações sobre o cliente (clipping), entre outras atividades que focam e destacam o papel de intermediador da assessoria no relacionamento com a mídia.

De qualquer modo, se o que esperar de um profissional no papel de assessor de imprensa parece já sedimentado nas orientações jornalísticas, na prática, levando-se em conta as particularidades do mercado, essas funções nem sempre se confirmam. 0 levantamento de Mick (2013) sobre o perfil do profissional do jornalismo brasileiro mostrou que muitos jornalistas que atuam como assessores de imprensa acabam exercendo funções muito diferentes destas apresentadas, incluindo desde a produção de produtos de publicidade e o marketing político até a atuação em cerimoniais ou mesmo a atuação como motorista.

Nesse sentido o estudo aqui apresentado busca compreender como este setor está se caracterizando numa cidade média no interior do Maranhão; isso porque, levando-se em conta as características do mercado local - uma cidade média de interior, no Maranhão, um dos estados mais pobres do Nordeste e do Brasil (IBGE, 2018b) -, a proposta de entender como se configura aí a atividade de assessor de imprensa é um modo de enxergar a própria formação e as particularidades locais no que tange ao trabalho do jornalista.

\section{Procedimentos metodológicos}

Esta pesquisa consiste em um estudo quantitativo que se orienta pelo modelo cartográfico. Para chegar aos profissionais para aplicação do questionário, foi realizada uma pesquisa exploratória com várias etapas, tendo incluído o conhecimento empírico de uma das pesquisadoras, que atuou na área por quatro anos, além de pesquisas no Google com as palavras-chave Assessoria de imprensa e Imperatriz. A lista inicial, por exemplo, foi organizada por meio de busca por possíveis páginas oficiais de empresas e órgãos que tivessem assessoria, bem como por consultas via telefone para confirmar os dados 
encontrado na internet. Também foi levada em consideração a lista dos alunos do curso de especialização em Assessoria de Imprensa Empresarial da UFMA, do qual vários atuam como profissionais nesse ramo. Por fim, foi solicitado aos próprios profissionais encontrados no levantamento exploratório que apontassem colegas que trabalhassem na área.

Como resultado desse mapeamento, chegou-se a uma lista com 37 profissionais que atuavam em 21 organizações, entre as quais órgãos públicos (Executivo e Legislativo), diretamente com políticos, Ministério Público, empresas de comunicação que prestam o serviço, empresas privadas que contam com assessoria própria, instituições representativas e estabelecimentos de ensino superior. 0 Quadro 1 apresenta de forma mais detalhada a distribuição de profissionais que atuam no mercado de Imperatriz.

Quadro 1 - Lista de empresas com setor de assessoria de imprensa

\begin{tabular}{|l|c|c|}
\hline \multicolumn{1}{|c|}{ Organização/Pessoa } & Tipo de empresa & No de profissionais \\
\hline Prefeitura & Pública & 10 \\
\hline Secretaria de Estado da Infraestrutura & Pública & 1 \\
\hline Ministério Público Estadual & Pública & 5 \\
\hline Câmara Municipal & Pública & 1 \\
\hline Cemar & Privada & 1 \\
\hline Suzano - Papel e Celulose & Privada & 1 \\
\hline Deputado Léo Cunha & Pública & 1 \\
\hline Deputado Marco Aurélio & Pública & 1 \\
\hline Sinproesemma & Terceiro Setor & 1 \\
\hline Fiema & Terceiro Setor & 1 \\
\hline Sebrae & Terceiro Setor & 1 \\
\hline ACII & Privada & 1 \\
\hline Unisulma & Privada & 1 \\
\hline Fest & Privada & 1 \\
\hline Ceuma & Privada & 1 \\
\hline UEMASUL & Pública & 1 \\
\hline UFMA & Pública & \\
\hline CDL & Terceiro Setor & 1 \\
\hline Tocantins Shopping & Privada & \\
\hline Palavra Comunicação & Privada & 1 \\
\hline Canal Comunicação & Privada & 1 \\
\hline 9Talk & Privada & 1 \\
\hline
\end{tabular}

Fonte: Elaborado pelas autoras.

Só esse breve levantamento dos setores que utilizam esse serviço na cidade permite adiantar que o campo que mais emprega é o setor público ${ }^{2}$. Vários fatores contribuem para esse resultado: em primeiro lugar, o pioneirismo da atividade estatal na implantação de uma assessoria no município - a primeira assessoria organizada em Imperatriz foi a da Prefeitura

\footnotetext{
${ }^{2}$ Vale ressaltar que aqui não foram mapeados os clientes atendidos por empresas de assessoria que contratam serviços de jornalistas terceirizados, o que ampliaria ainda mais o número de profissionais que atuam nessa área. Os terceirizados não foram incluídos no levantamento por entender-se que, neste caso, as condições de trabalho são oferecidas pela empresa de comunicação e não pelo cliente, o que foge da proposta do artigo.
} 
- e, em segundo lugar, a própria mídia da cidade, que não tem uma produção crítica muito consolidada $^{3}$, o que inibe substancialmente as iniciativas de outras empresas em investir num setor específico de comunicação, particularmente na assessoria de imprensa. Além disso, contribui para esse volume de empregos o fato de a assessoria dos órgãos públicos receber funcionários vindos de indicações e servidores que são concursados em outros setores administrativos, mas que, com a formação em Jornalismo, solicitam a transferência para a área específica de conhecimento.

Outro ponto que chama atenção é que a maior parte das organizações catalogadas conta com atuação de apenas um profissional, o que pode demonstrar uma precarização do trabalho, já a dimensão da equipe parece ser incompatível com a demanda de trabalho exigida, ou seja, há muitas tarefas poucos profissionais para executá-las.

Como destaca Dantas (2014), a precarização diz respeito a um conjunto de condições de trabalho que dificultam o exercício efetivo de uma prática profissional. Ao levantar os tipos mais comuns de precarização a que são submetidos os profissionais que atuam no jornalismo, Druck (2011) elenca pelo menos seis tipos: (1) vulnerabilidade na inserção no mercado; (2) aumento de funções exigidas e de terceirização do trabalho; (3) insegurança e más condições de saúde para exercer a função; (4) perda da identidade; (5) fragilização dos sindicatos; e, por fim, (6) perda dos direitos trabalhistas. Nesta pesquisa a precarização que o número reduzido de profissionais aponta é a de segundo tipo, que pressupõe a intensificação do trabalho e o acúmulo de funções. Só para exemplificar, a assessoria de imprensa na Universidade Federal do Maranhão, que atende nove cursos de graduação, duas especializações lato sensu e seis especializações stricto sensu (cinco mestrados e um doutorado), só conta com um jornalista responsável.

Druck (2011) aponta, inclusive, ao discutir as condições de trabalho da profissão, baixos salários, carga horária longa e acúmulo de funções como indícios importantes da precarização do jornalismo. Some-se a isso o fato de que a própria digitalização da informação e das relações, na avaliação de Mizukami, Reia e Varon (2014), ajuda a reforçar esse cenário, demonstrando que a realidade local não está dissociada do cenário de mercado como um todo.

\footnotetext{
Alguns jornalistas, apesar de reconhecerem as oportunidades oferecidas pela digitalização, destacam que suas condições de trabalho foram negativamente impactadas ao longo da última década, uma vez que são obrigados a fazer horas extras e a assumir novas funções para atender às demandas [...] (MIZUKAMI; REIA; VARON, 2014, p. 78).
}

\footnotetext{
${ }^{3}$ Não há sites de cobertura jornalística local e as produções dos dois jornais impressos $O$ Correio e $O$ Progresso são pautadas, majoritariamente, em releases do Governo do estado e da Prefeitura, respectivamente.
} 
Figaro, Nonato e Grohmann (2013) corroboram essa reflexão. Segundo a autora, “As mudanças tecnológicas apropriadas no fazer jornalístico redesenharam as maneiras de se trabalhar. As redações ganharam outro formato, outro ritmo, muitas profissões desapareceram [...]" (FIGARO, NONATO E GROHMANN, 2013, p. 7).

Para além dessa apresentação, que mostra onde atuam os assessores da cidade, o estudo buscou diagnosticar o perfil desses profissionais. Para isso foi aplicado um questionário semiestruturado, com 23 questões abertas, fechadas ou de múltipla escolha. As indagações versaram sobre dados socioeconômicos, formação, experiência profissional, remuneração, condições de trabalho e grau de satisfação com a área. As respostas permitiram traçar um panorama geral sobre o mercado e ver quem são os profissionais que atuam na área e como enxergam sua tarefa.

A forma escolhida para a aplicação do questionário online foi usar a ferramenta Google Forms, por seu emprego ser fácil e não exigir a visita a todos os entrevistados e por auxiliar na conversão dos dados em gráficos. Optou-se pela mescla de perguntas abertas e fechadas porque ela permite uma padronização nas respostas sem que se percam as oportunidades de complementação por parte dos sujeitos da pesquisa.

0 questionário online foi enviado para os 37 profissionais mapeados. Desses, 32 responderam, o que representa $86,5 \%$ do total, ou seja, uma amostra que permite inferências sobre o universo geral (GEHLEN, 2014). O link para acessar as questões foi enviado por mensagem, por meio da rede social Facebook, por e-mail e via WhatsApp. 0 préteste foi feito no início de maio de 2017 e o tempo médio de resposta da pesquisa efetiva ficou em quatro dias.

Ainda no âmbito metodológico, foram realizadas três entrevistas de profundidade com os pioneiros do setor na cidade. As conversas, gravadas, foram dirigidas aos proprietários das empresas Canal Comunicação, a primeira a ofertar o serviço em Imperatriz; ao proprietário da Palavra Comunicação, a primeira a atuar especificamente em assessoria de imprensa, e ao jornalista Gil Carvalho, um dos mais antigos profissionais em atividade na área. 0 intuito dessas conversas foi conhecer mais a trajetória da área na cidade, bem como documentar essa história, já que não foram encontrados relatos publicados sobre esse assunto em livros e/ou em outras pesquisas dos acervos consultados na UFMA e na Academia Imperatrizense de Letras. 


\title{
3 A formação do mercado de assessoria imperatrizense
}

De acordo com informações coletadas pelas entrevistas que compõem este levantamento, duas tendências marcaram a história da implementação do setor local: em primeiro lugar, o trabalho de jornalistas que atuavam nos veículos na cidade e que começaram a prestar serviços de assessoria, principalmente na área política, e em segundo lugar, de forma paralela, iniciativas voltadas para o setor empresarial, realizadas por grupos que passaram a oferecer serviços de comunicação de forma dirigida.

No início dos anos 2000, apenas a Prefeitura de Imperatriz, a Câmara Municipal e o Governo do Estado já tinham de alguma forma a presença de profissionais para realizarem assessoria de imprensa, fato que variava de administração para administração. Um pouco antes, na década de 1990, Imperatriz passou por um processo de divisão territorial que deu origem a novas cidades na região ${ }^{4}$. Algumas dessas novas prefeituras e câmaras de vereadores começaram a ter suas próprias assessorias, mesmo que de forma precária. Um exemplo foi o trabalho do jornalista Gil Carvalho, que desde 2004 prestava serviço de assessoria para várias cidades do entorno de Imperatriz.

\begin{abstract}
Cheguei a exercer cinco assessorias de uma única vez, que eram Montes Altos, Davinópolis, Governador Edison Lobão - Prefeitura e Câmara - e logo em seguida apareceu a assessoria da campanha para o Dr. Pádua, fui assessor (dele) de deputado estadual e federal. E aí eu comecei a me especializar na área de assessoria política. (Informação verbal)
\end{abstract}

O levantamento realizado para este artigo dá conta, ainda, de que a primeira empresa a prestar serviços de assessoria em Imperatriz foi a Canal Comunicação, uma agência de Publicidade e Propaganda que atua na cidade há mais de 20 anos. 0 departamento de assessoria foi criado em 2007 para atender uma demanda específica da Companhia Energética do Maranhão (Cemar), que tinha passado pelo processo de privatização e queria fazer um trabalho voltado para Imperatriz e para a região visando a uma melhoria da imagem e a uma consolidação da nova identidade da empresa. Além da assessoria, a Canal Comunicação foi a primeira a contar com o serviço de monitoramento de mídia.

Nós sempre atuamos na área de Propaganda e Publicidade. [...] e me fizeram a proposta para o desafio de montar uma assessoria de imprensa em Imperatriz e região. Como eu sou empreendedor, fui estudar o que seria

\footnotetext{
${ }^{4}$ De acordo com historiador Adalberto Franklin (2008), Imperatriz teve seu território reduzido a metade após a emancipação dos municípios de Açailândia, João Lisboa, Davinópolis, Ribamar Fiquene, Governador Edison Lobão, São Francisco do Brejão, Cidelândia, Vila Nova dos Martírios e São Pedro da Água Branca.
} 
isso. E aí com a ajuda de algumas pessoas que eram ligadas à gente, alguns jornalistas, a gente encontrou um formato e iniciamos o trabalho que seria o trabalho de assessoria (informação verbal).

Morais (2010) relata que, a partir de 2008, o curso de Jornalismo implementou em Imperatriz a assessoria de imprensa da UFMA. 0 setor da universidade, que se iniciou como projeto de extensão, a partir de 2011 foi efetivamente instalada de forma independente, sob coordenação de uma jornalista concursada. Para além dessa iniciativa, o curso de Jornalismo possibilitou a entrada de mais profissionais no mercado, o que gerou a ampliação do número de vagas e iniciativas no setor. Um exemplo foi a criação, em 2012, da Palavra Comunicação, a primeira empresa especializada em assessoria de imprensa em Imperatriz.

Até então o mercado jornalístico local era muito pouco explorado, era um cenário muito diferente de hoje, onde você encontra os profissionais para atender as diversas demandas que você possa ter. Naquela época os empresários sequer sabiam que jornalistas poderiam fazer alguma coisa de comunicação para eles (informação verbal).

Depois dessas iniciativas e da inserção de novos jornalistas no mercado local, outros empreendimentos surgiram: a Prensa Comunicação (fundada em 2013), a Nova Assessoria de Imprensa (fundada em 2015) e a Pimenta Assessoria de Imprensa (fundada em 2017). Hoje 21 organizações, entre públicas, privadas e do terceiro setor, atuam no município.

Apesar de uma rápida expansão, o campo sofreu e ainda sofre para se consolidar. Entre as dificuldades apontadas, estava a falta de compreensão, por parte dos empresários e dos agentes políticos, sobre o que faz a assessoria de imprensa e qual é sua importância.

0 mercado não tinha ideia do que era uma assessoria. Com o trabalho da Cemar aparecendo, que então era uma empresa que não dava retorno a ninguém, a assessoria começou a dar lucro e isso mudou a imagem da empresa. E acabou que outras empresas começaram a nos procurar (informação verbal).

Hoje, talvez o maior desafio dos profissionais de assessoria de imprensa, de um modo geral, seja menos definir seu papel e mais expandir sua atuação para atender e gerenciar as demandas no ciberespaço.

[...] reduziu muito nos últimos anos, em função do crescimento das mídias sociais, o interesse por uma assessoria de imprensa, especificamente aquela tradicional em que a gente falava de release para jornal, de 
agendamento de entrevista em televisão ou tentativa disso porque agora o maior interesse é que tenhamos uma boa produção de conteúdo para empresas para falar com o seu público diretamente nas redes sociais (informação verbal).

No campo da assessoria política, isso é bastante sintomático na região. É comum encontrar grupos no Facebook e no WhatsApp que servem como plataforma de divulgação de informações das ações dos agentes políticos. “Tem gestor hoje na região que só quer que você faça assessoria de imprensa se você tiver pelo menos 100 grupos de WhatsApp. Para eles não é mais interessante a imprensa tradicional." (CARVALHO, 2017, informação verbal). Estas mudanças em curso são sentidas em todos os setores que possuem assessoria de imprensa.

\section{Análise dos resultados: quem é o assessor na segunda maior cidade do Maranhão}

A primeira questão foi o nome dos participantes. Embora a identificação não fosse o mote do levantamento, serviu de controle da amostra coletada, já que o questionário foi direcionado para uma lista definida de profissionais. Outra variável detectada na análise foi a idade. Das 32 respostas obtidas, 25 delas mostraram que esses trabalhadores têm entre 26 anos e 35 anos, o que representa 78,1\% do total. Em seguida aparecem os assessores mais jovens, quatro com idades entre 18 anos e 25 anos, que representam 12,5\% do total. Por fim, apenas três profissionais já passaram da casa dos 35 anos, dos quais dois têm de 36 anos a 45 anos e um tem mais de 45 anos. Ou seja, um grupo jovem.

Quanto ao gênero dos entrevistados, o levantamento revelou que o número de mulheres que trabalham com assessoria de imprensa representa 71,9\% do total, com 23 respostas, enquanto apenas nove homens da amostra coletada afirmaram trabalhar na área. Esse fenômeno confirma o já apontado pelos resultados da pesquisa de Mick e Lima (2013), que, ao traçar o perfil do jornalista brasileiro, descobriu na amostra estudada, que 64\% são mulheres; e é semelhante ao resultado do levantamento de Silva (2016), o qual mostrou que 68,6\% dos graduados da UFMA são mulheres.

Não é possível identificar com os dados coletados a motivação exata para essa superioridade de mulheres nos cargos em assessoria de imprensa, porém a mudança pode ser atribuída ao fato de este ser o setor com maior expansão nos últimos anos. Após a formatura da primeira turma de Jornalismo na UFMA de Imperatriz, em 2011, por exemplo, 
apenas um jornal e um site foram criados na cidade: o jornal Correio Popular e o site Imirante.com, do grupo Mirante, que ganhou uma redação regional. Ocorreram outras iniciativas que não se mantiveram, como o site Do Minuto, que foi desativado em 2014. No entanto, como apresentamos neste estudo, as oportunidades no âmbito da comunicação empresarial e institucional foram significativamente ampliadas.

Com relação à naturalidade do assessor, percebeu-se que a maioria é maranhense, sendo que ao todo 18 participantes afirmaram ser naturais de Imperatriz, especificamente. Entre as cidades maranhenses citadas estão Caxias, Coroatá e Santa Inês, e aparecem também os estados vizinhos do Pará, do Tocantins e do Piauí. Apenas um participante do Sudeste apareceu no questionário, e dois não responderam a essa questão. Esse dado mostra que o mercado, principalmente a assessoria de imprensa, tem absorvido os profissionais da cidade.

Quanto ao estado civil, temos uma superioridade expressiva do número de solteiros, com 24 respostas, o que representa $75 \%$ do total. Em segundo lugar aparecem cinco que afirmam ser casados (15,6\%) e três, divorciados. Provavelmente, a composição predominante de jovens na amostra justifica a superioridade numérica dos solteiros. Esse dado segue a tendência nacional apontada pela Pesquisa Nacional por Amostra de Domicílios (IBGE) de 2015, na qual o Nordeste aparece como a segunda região com a maior proporção solteiros do país, com $56,7 \%$.

No que se refere à formação, tem-se uma superioridade dos profissionais formados em Jornalismo, com 28 respostas, o que representa 87,5\% do total. Ainda com formação superior em outras áreas, temos três profissionais $(9,4 \%)$, graduados em Pedagogia, Letras e Direito. De todos os profissionais graduados em Jornalismo, 17 afirmaram possuir pósgraduação, sendo 16 com especialização e um com mestrado. Apenas um dos entrevistados afirmou não possuir formação superior e cinco estão com cursos em andamento, quatro com graduação em Jornalismo, um com graduação em Direito. Isso demonstra que, substancialmente, o jornalista é o assessor de imprensa na cidade, mas também que esse profissional, para além da graduação, busca o aprimoramento cursando pós-graduação.

Outro dado levantado foi a data de término da graduação. 0 ano de 2013 foi citado na maioria das respostas, sendo oito profissionais formados naquele ano. Em seguida apareceram 2007, 2015 e 2016, com três respostas em cada. Essa informação ratifica outro dado do levantamento - que a média de idade dos assessores se encontra entre 26 anos e 35 anos. Apenas um dos entrevistados afirmou ter concluído a formação antes dos anos 2000, com graduação em 1995. Ainda no âmbito da formação, foi verificada a instituição na qual cada profissional cursou sua graduação. Do total das respostas, 24 incluíram os que 
estudaram ou estão estudando na UFMA de Imperatriz, o que representa $70,6 \%$ do total. Seguiram as outras instituições citadas com até duas respostas: Universidade Estadual do Maranhão (UEMA)- que agora é Universidade Estadual do Sul do Maranhão (Uemasul)-, Faculdade de Imperatriz (Devry/Facimp), UFMA de São Luís, Faculdade São Luís, Universidade Federal do Piauí (UFPI), Universidade Federal do Tocantins (UFT), Universidade Estadual do Tocantins (Unitins) e Universidade Cásper Líbero. Um dado interessante é que apenas três instituições privadas apareceram no levantamento, demonstrando que a maior parte desses profissionais cursou a graduação em instituições públicas de ensino.

Tratando-se especificamente do trabalho de assessor, foi perguntado em qual tipo de empresa esse profissional atua. As instituições públicas foram citadas por 15 profissionais, o que representa $46,9 \%$ do total, seguidas das empresas particulares, citadas por 12 , ou seja, 37,5\%. Já o terceiro setor apareceu em quatro respostas $(12,5 \%)$. As seções públicas e privadas aparecem de forma equilibrada no número de profissionais atuantes. Do setor público com assessoria, a área da política é o espaço que mais emprega. Vale destacar que apenas a prefeitura conta com 10 profissionais entre os questionários respondidos. Também aparecem no mapeamento o Governo de Estado, o Ministério Público Estadual, a Câmara de Vereadores, a UFMA e a UEMA. Entre as empresas privadas, foram citadas a Companhia Energética do Maranhão (Cemar), a Suzano, as faculdades particulares Unidade de Ensino Superior do Sul do Maranhão (Unisulma), Centro de Ensino Avançado do Maranhão (Ceuma) e Faculdade de Educação Santa Terezinha (Fest), o Shopping Tocantins e as empresas de comunicação Canal, 9Talk e Palavra. No terceiro setor, foram citados sindicatos, a Federação das Indústrias do Estado de Maranhão (FIEMA) e a Associação Comercial e Industrial de Imperatriz.

É necessária uma ressalva quanto ao total de empresas que possuem assessoria de imprensa na cidade, pois não foram mapeadas neste trabalho as organizações que são clientes das empresas que trabalham especificamente com comunicação. Esta opção está embasada no fato de serem as empregadoras que oferecem as condições de trabalho, que são objeto deste estudo.

0 resultado demanda outra reflexão: talvez a menor incidência de empresas privadas a contratarem uma assessoria seja reflexo direto da pouca oferta de veículos de imprensa, boa parte deles sem uma produção crítica ${ }^{5}$.

\footnotetext{
${ }^{5}$ Um exemplo disso é a replicação de releases, que é recorrente nos veículos da cidade, principalmente nos jornais impressos. Em um estudo sobre essa prática, Gehlen (2015) analisou as matérias sobre a Exposição Agropecuária de Imperatriz entre os meses de junho e julho de 2012, publicadas nos jornais O Progresso e Correio Popular. Ao todo foram 69 textos publicados nesse período; destes, 54 são cópias na íntegra de textos enviados por assessoria e somente 11 textos são de autoria dos veículos.
} 
Quanto ao vínculo empregatício desses profissionais, a pesquisa constatou que 26 dos que responderam são funcionários próprios das organizações onde trabalham. Neste recorte encontram-se os concursados, que totalizam oito profissionais, mas apenas dois desses são para cargos da comunicação, ou seja, foram remanejados de outras áreas. Um caso peculiar é a formação da assessoria de imprensa da Prefeitura, que conta com profissionais que foram concursados em outras áreas, mas que, por possuírem a graduação em Jornalismo, foram realocados para cumprirem a função de assessor. Tem-se apenas um que afirmou ser terceirizado. Há, ainda, um servidor público nomeado e um assessor comissionado. Ou seja, há demanda reprimida para concurso na área.

Com relação ao salário, o cenário apresenta um equilíbrio entre os profissionais que afirmam ganhar até dois salários mínimos e os que afirmam ganhar até três salários mínimos: 10 para cada resposta; juntos, representam 62,5\% do total. Temos ainda profissionais que recebem até 4 salários mínimos (seis profissionais - 18,8\%) e mais de cinco (três profissionais - 9,4\%). Um dado alarmante, mesmo pequeno comparado com o número total, é que dois profissionais afirmam ganhar apenas um salário mínimo. Este dado estabelece que do total de resposta, temos 12 (37,5\%) profissionais com remuneração abaixo do piso para os jornalistas no Maranhão de acordo com a Fenaj (R\$ 2.433,38 para data-base 2015/2016), que seria aproximadamente 2,5 salários mínimos.

Gráfico 1 - Renda dos profissionais.

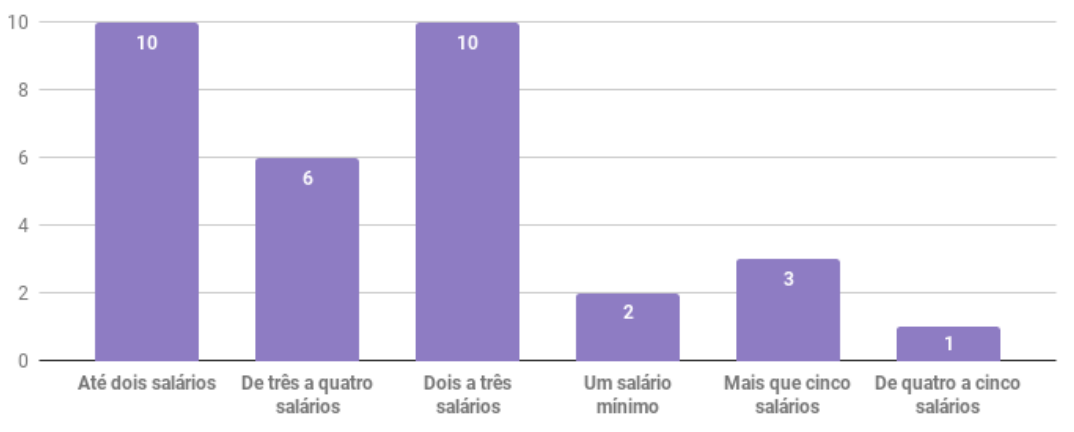

Fonte: Dados da pesquisa.

A carga horária foi outro aspecto observado. Tem-se aqui um cenário que indica uma sobrecarga de trabalho desses profissionais: 19 responderam que trabalham entre oito e dez horas por dia, o que representa $59,4 \%$ do total. Esse tempo ultrapassa a carga horária mínima do jornalista, que é de cinco horas; a máxima, de sete horas e, inclusive, o horário comercial padrão no país, que estabelece oito horas diárias de trabalho. Nove profissionais afirmam que trabalham entre 5 a 7 horas, sendo estes $28,1 \%$ do total. Empatam dois que 
trabalham 5 horas e dois que trabalham mais de 10 horas por dia (cada um dos quais 6,3\%), fato também espantoso, visto que a remuneração é baixa.

A quantidade de horas trabalhadas pode ser apontada como um dos pontos mais críticos na assessoria de imprensa em Imperatriz, pois é exigida dedicação exclusiva e disponibilidade full time para atender demandas em qualquer horário, inclusive em finais de semana. Esta é até mesmo uma das principais reclamações dos profissionais ouvidos, já que existe uma discrepância entre a remuneração que, como vimos é em 37,5\% dos casos inferior ao piso para o estado, e a carga horária.

0 tempo de experiência na área trabalhada também foi averiguado e aqui se tem a informação de que a maior parte dos profissionais entrevistados conta até cinco anos de experiência na área, totalizando 15 respostas. Em seguida aparecem os assessores com até dez anos trabalhando na área, com 11 respostas, e quatro apenas com experiência de até 15 anos. Dado o grande número de profissionais jovens, alguns ainda em formação, é compreensível que os profissionais não tenham tanto conhecimento do campo em questão.

Quanto à experiência em outros departamentos da Comunicação, constatou-se que 21 dos 32 profissionais já atuaram em outras áreas ou mídias (rádio, TV, impresso, internet e docência), totalizando 65,6\% da amostra, e 11 têm experiência apenas em assessoria, o que representa 34,4\% do total. Do ponto de vista do trabalho, a experiências em outros setores da Comunicação é interessante, pois possibilita um conhecimento melhor das rotinas de produção dos veículos e também de quem são os profissionais da imprensa, e isso ajuda, em tese, no processo de relacionamento e de divulgação da marca assessorada.

Um dos pontos de maior curiosidade desta pesquisa foi saber quais atividades os profissionais que trabalham em assessoria em Imperatriz exercem. Para isso foi listada uma série de ações próprias de área, que são reconhecidas como sendo de responsabilidade dos assessores, com base no Manual de Assessoria de Imprensa da Fenaj (2007). Foram acrescentadas algumas atividades que fogem ao escopo da profissão, mas que muitas vezes são acumuladas pelos assessores. Ao todo foram listadas 14 atividades. 0 levantamento revelou que as atividades rotineiras e mais tradicionais da área de assessoria de imprensa foram as mais citadas, entre as quais se destacaram a produção de releases, a sugestão de pauta, a cobertura fotográfica, a criação e manutenção de mailing list. Outra atividade vem ganhando destaque no mercado é a de gestor de plataformas digitais, aqui descrita pelos entrevistados como social media. Essa tem sido uma demanda crescente das empresas, que cada vez mais estão presentes com perfis em sites de redes sociais, o que exige planejamento, produção de conteúdos e monitoramento específicos. Dos 32 entrevistados, 22 afirmam exercer atividades relacionadas às mídias sociais. 
Outro fato que chamou a atenção foi o número expressivo de atividades que são executadas na rotina produtiva dos assessores e que extrapolam o escopo da área, como trabalhos relacionados ao cerimonial e à organização de eventos. 0 resultado ratifica a constatação de que ainda há muita confusão sobre qual é, efetivamente, o papel do assessor de imprensa.

Gráfico 2 - Atividades exercidas pelos assessores

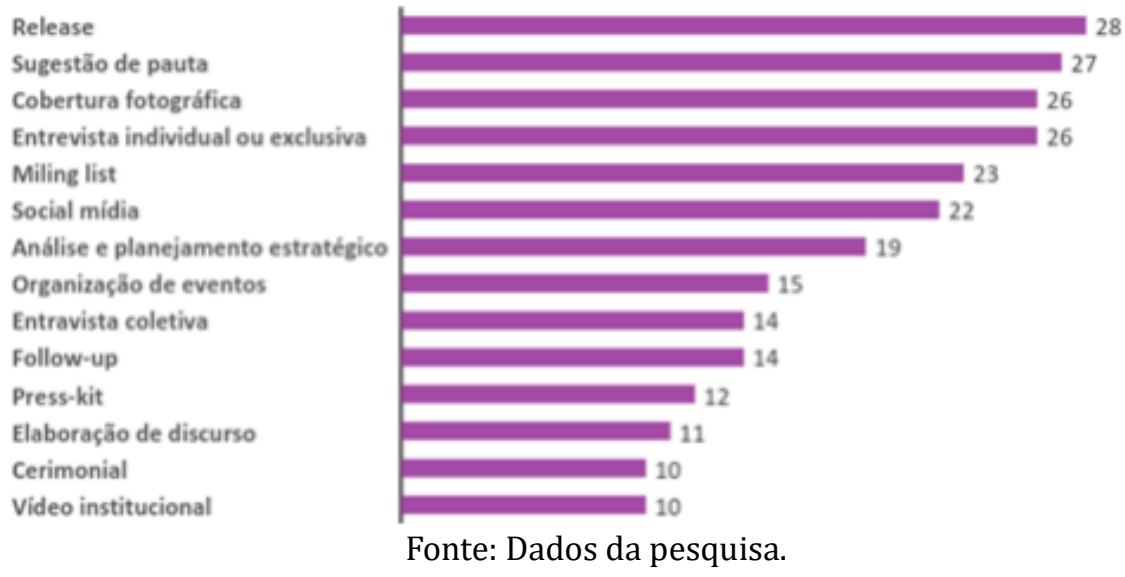

Para ter uma dimensão do tamanho do departamento de comunicação em que os assessores da cidade atuam, foi perguntado a eles quantas pessoas integram sua equipe, entre profissionais e estagiários. A maioria respondeu que trabalha sozinha, ou seja, são eles mesmos o próprio setor, o que ilustra bem a situação da área na cidade. Por mais que a demanda seja pequena, alguns trabalhos como design gráfico ou campanhas de marketing sobrecarregam esses profissionais, haja vista o tempo que dedicam ao trabalho, que passa de oito horas diárias, conforme dado anteriormente apresentado.

Em relação às dificuldades da função de assessor, a pesquisa constatou que a definição do trabalho da assessoria ainda é uma barreira enfrentada pelos profissionais de Imperatriz. Essa crítica apareceu em 40,6\% das respostas. Em seguida, foi citada a estrutura física do local de trabalho (em 31,3\% das respostas), que não atende a todas as necessidades desses profissionais. É comum que esses profissionais tenham que utilizar equipamentos e veículos próprios no trabalho e, em alguns casos, esses itens são requisitos para seleção. 0 relacionamento com a imprensa também aparece como uma dificuldade em 12,5\% das respostas.

Outro ponto da pesquisa foi medir o grau de satisfação do profissional nos seguintes aspectos: trabalho em assessoria de imprensa; remuneração; condições de trabalho e crescimento profissional. Estes pontos foram escolhidos porque permitem conhecer mais como é relação dos profissionais com seu batente do ponto de vista mais pessoal. Pouco 
mais da metade dos entrevistados $(53,1 \%)$ disse estar satisfeita trabalhando na área, seguida de 18,5\% que disseram não estar nem satisfeitos, nem insatisfeitos. Seguem empatados em $12,5 \%$ os que estão insatisfeitos e os que estão muito insatisfeitos. Avaliando o panorama geral, o profissional de assessoria de imprensa acredita que trabalhar nessa área é bom, apesar dos obstáculos já apresentados. Vale ressaltar que essa área é a que mais emprega os jornalistas na cidade e ela também permite que esses profissionais tenham o próprio negócio de forma mais facilitada do ponto vista jurídico, por exemplo, já que não é necessária uma concessão para isso, ou mesmo estrutural, já que isso não depende, como o jornal, da impressão, cujo custo inviabiliza alguns projetos.

No que se refere à remuneração, a maioria fica entre os que estão indiferentes e os que estão insatisfeitos, com respectivamente $34,4 \%$ e $31,3 \%$. Os satisfeitos são $21,9 \%$. Vale lembrar que os profissionais ganham uma média de até três salários mínimos. Quanto às condições de trabalho, a satisfação é maior, com 46,8\%, seguidos por $28,1 \%$ de indiferentes e por 15,6\% que estão insatisfeitos. Este dado é de certa forma incoerente, já que a estrutura física do local de trabalho foi apontada como um dos principais obstáculos enfrentados, juntamente com a alta carga horária. Isso pode ser reflexo, talvez, de certo conformismo com as condições trabalho: os profissionais contratados acabam se adaptando ao que é disponibilizado pelo empregador e chegam mesmo a utilizar os próprios equipamentos para o trabalho, como já se disse.

$\mathrm{Na}$ perspectiva de crescimento profissional, percebe-se um equilíbrio entre as opiniões dos profissionais: há $28,1 \%$ satisfeitos e também $28,1 \%$ nem satisfeitos, nem insatisfeitos. Por sua vez, 25\% estão insatisfeitos e 18,8\% estão muito satisfeitos. Apesar das condições adversas apontadas nas respostas, esses profissionais ainda têm confiança no mercado local e na possibilidade de explorar campos ainda poucos cogitados, como a assessoria específica para as redes sociais.

A última questão aplicada foi aberta e pedia que profissionais apontassem o que precisava ser melhorado no trabalho do assessor de imprensa em Imperatriz. A valorização do profissional é uma das melhorias mais citadas pelos entrevistados, visto que a falta de conhecimento dos empregadores e até dos colegas quanto à real função do assessor é apresentada como a maior dificuldade. Remuneração, carga horária e condições estruturais também são indicadas. Como pondera um os entrevistados "Melhorar a estrutura física das empresas para que o jornalista tenha suporte adequado para exercer suas funções básicas e suporte para o monitoramento das notícias." (ASSESSOR 10). A valorização do trabalho também foi frequente nas respostas: "As pessoas devem entender o papel do assessor e valorizar esses profissionais (tanto economicamente quanto na importância da função, que 
estão de certa forma ligadas). Vejo um avanço e profissionalização do mercado na cidade, que ainda precisa evoluir, mas que já demonstra bons resultados" (ASSESSOR 17).

Por fim, a partir dos conjuntos das repostas, é possível ter uma noção da realidade do campo na cidade, bem como traçar alguns paralelos sobre seus avanços e seus desafios.

\section{Considerações finais}

0 mercado de trabalho em assessoria de imprensa em Imperatriz ainda é bem recente, o que se, por um lado, ainda deixa brechas para dificuldades de estabilização e reconhecimento por parte do profissional, por outro é um indicativo de que há muito a buscar. Se levarmos em conta as dificuldades de emprego, a baixa oferta de vagas, não só em Imperatriz, mas em todo o país no âmbito do jornalismo, haver um local com tantas oportunidades de trabalho a serem implementadas configura-se uma espécie de oásis para jornalistas empreendedores ou mesmo para os que sonham com uma vaga na área por meio de concurso público, haja vista que essa é uma lacuna evidente.

Mesmo com todas as adversidades que o campo tem passado, particularmente por conta da não obrigatoriedade do diploma para atuação, a formação superior em Jornalismo se mostra um diferencial real na configuração de um mercado ainda em processo de construção. A chegada do curso de jornalismo na UFMA de Imperatriz, por exemplo, foi um divisor de águas para o mercado e representa um marco para o desenvolvimento do cenário da comunicação institucional, com presença de profissionais dentro das organizações.

Apesar dos dez anos de curso de Jornalismo, temos ainda um desconhecimento dos empregadores e/ou clientes do que é o trabalho do assessor de comunicação. Aqui talvez caberia a sugestão de um trabalho mais próximo das entidades representativas, como o Sindicato de Jornalistas e Radialistas de Imperatriz (Sindijori), e da própria universidade, no sentido de auxiliar nesse esclarecimento.

Para além das questões relativas ao mercado, este estudo ratifica o papel relevante da cartografia como método de estudo para as Ciências Sociais Aplicadas. Ao traçar um perfil dos profissionais que trabalham em assessoria em Imperatriz, é possível conhecer vários aspectos específicos do mercado local, mas também levantar outras questões a serem aprofundadas adiante. Não cabe aqui dar respostas definitivas, há vários pontos ainda a serem abordados como o desenvolvimento das rotinas dentro das organizações. É válido, por exemplo, ouvir os donos das empresas que possuem assessoria para saber o que eles 
esperam desses profissionais e tentar compreender por que tantos assessores reclamam da falta de entendimento de seu trabalho por parte de quem contrata.

Por fim, ao realizar essa pesquisa, ciente do papel relevante da assessoria como o setor que mais emprega jornalistas na cidade, este estudo aponta para uma necessidade de outros levantamentos e de novos projetos acerca desse tema, ainda pouco estudado na universidade. A própria história da assessoria na cidade ainda carece de estudos e é hoje encontrada apenas em registros não organizados entre um trabalho e outro ou na lembrança de seus personagens. Por fim, ao findar este estudo, acreditamos ter aberto uma porta para novas investidas e contribuído com um registro inicial da prática na cidade.

\section{Referências}

CARVALHO, Gil. Entrevista concedida pelo jornalista para este artigo. Imperatriz, 27 jun.2017.

CHAFI, Braide Junior. Entrevista concedida proprietário da Canal Comunicação para este artigo. Imperatriz, 9 jun.2017.

CHAPARRO, Manuel Carlos. Cem anos de Assessoria de Imprensa. In: DUARTE, Jorge (org.). Assessoria de imprensa e relacionamento com a mídia: teoria e técnica. São Paulo: Atlas, 2009. p. 33-51.

CHINEM, Rivaldo. Assessoria de imprensa: como fazer. São Paulo: Summus, 2003.

DANTAS, Juliana. Perspectivas da prática profissional do jornalista assessor de imprensa: 0 ethos, a identidade e as reflexões deontológicas no contexto da atuação simultânea em redações e assessorias de imprensa de Natal-RN. 2014. Dissertação (Mestrado em em Estudos da Mídia) Programa de Pós-Graduação em Estudos da Mídia, Universidade Federal do Rio Grande do Norte, Natal, 2014.

DRUCK, Graça. Trabalho, precarização e resistências: novos e velhos desafios? Caderno CRH, Salvador, v. 24, n. 1, p. 37-57, 2011.

DUARTE, Jorge. Assessoria de imprensa e relacionamento com a mídia. São Paulo: Atlas, 2009.

FENAJ. Manual de assessoria de comunicação/imprensa. Brasília: FENAJ, 2007.

FRANKLIN, Adalberto. Apontamentos e fontes para a história econômica de Imperatriz. Imperatriz: Ética, 2008.

FIGARO, Roseli; NONATO, Cláudia; GROHMANN, Rafael. As mudanças no mundo do trabalho do jornalista. São Paulo: Atlas, 2013. 
Porto Alegre: EdiPUCRS, 2015. p. 59-80.

GEHLEN, Marco Antonio. Amostragem e Inferência nas Pesquisas em Jornalismo. Anais do XV Congresso de Ciências da Comunicação na Região Sul, 2014, Palhoça. p. 1-12.

IBGE - INSTITUTO BRASILEIRO DE GEOGRAFIA E ESTATÍSTICA. Pesquisa nacional por amostras de domicílios - síntese de indicadores de 2013. Rio de Janeiro, 2015.

IBGE - INSTITUTO BRASILEIRO DE GEOGRAFIA E ESTATÍSTICA. População residente segundo as unidades da Federação. Diário Oficial da União, 2018a, nำ167, p. 55.

IBGE - INSTITUTO BRASILEIRO DE GEOGRAFIA E ESTATÍSTICA. Síntese de indicadores sociais: uma análise das condições de vida da população brasileira. Rio de Janeiro: 2018b.

KOPPLIN, Elisa; FERRARETO, Luiz Artur. Assessoria de imprensa: teoria e prática. 5. ed. Porto Alegre: Sagra-DC Luzzato, 2009.

MAFEI, Maristela. Assessoria de imprensa: como se relacionar com a mídia. São Paulo: Contexto, 2008.

MAG. Entrevista concedida pelo proprietário da Palavra Comunicação para este artigo. Imperatriz, 9 jun.2017.

MARTINUZZO, José Antônio. Seis questões fundamentais da assessoria de imprensa estratégica em rede. Rio de Janeiro: Muad, 2013.

MICK, Jackes. A precarização e o trabalho dos jornalistas brasileiros. In: ENCONTRO NACIONAL DE PESQUISADORES EM JORNALISMO, 11., 2013, Brasília. Anais [...]. Brasília: SBPJor, 2013. p. 168-169.

MICK, Jackes; LIMA, Samuel. Perfil do jornalista brasileiro: características demográficas, políticas e do trabalho jornalístico em 2012. São Paulo: Insular, 2013.

MIZUKAMI, Pedro; REIA, Jhessica; VARON, Joana. Mapeamento da mídia digital no Brasil. Rio de Janeiro: Escola de Direito do Rio de Janeiro da Fundação Getulio Vargas, 2014.

MORAIS, William Castro. 0 perfil do jornalista de Imperatriz nas emissoras de televisão, rádio e jornal impresso. 2010. Trabalho de Conclusão de Curso (Graduação em Comunicação Social) Universidade Federal do Maranhão, Imperatriz, 2010.

SILVA, Vanessa de P. M. Quem somos? Perfil do formado em Comunicação Social com habilitação em Jornalismo de Universidade Federal do Maranhão (UFMA) - Campus Imperatriz. 2016. Trabalho de Conclusão de Curso (Graduação em Comunicação Social) - Universidade Federal do Maranhão, Imperatriz, 2016. 


\title{
Career and work: who is the communication officer in Imperatriz (MA)?
}

\begin{abstract}
This article aims to build a profile of the professional who works in communication offices in Imperatriz, the second largest city in the state of Maranhão, Brazil. Our mapping presents the characteristics related to training, earnings, assignments and working conditions of the professionals who occupied that position in 2017. We have applied an online semi-structured questionnaire, composed of 24 questions, to 37 professionals that were identified as active in local job market, using the Google Forms tool. From these, we have received 32 replies. Results showed that the job market for communication officers in that city has grown exponentially in the last 10 years, creating, effectively, more Jobs for journalists, even though working conditions and salaries need improvements.
\end{abstract}

\section{Keywords}

Professional profile. Communication office. Imperatriz (MA). Mapping. Job market.

Recebido em 27/04/2018

Aceito em 06/06/2019 